\title{
Mathematical Simulation of Drying Process of Fibrous Material
}

\author{
Tomáš Blejchař ${ }^{1, *}$, Jiři Raška ${ }^{1}$, and Jana Jablonská ${ }^{1}$ \\ ${ }^{1}$ VŠB-Technical University of Ostrava, Faculty of Mechanical Engineering, Department of Hydromechanics and Hydraulic Equipment, \\ tř. 17 listopadu 15/2172, Ostrava-Poruba, Czech Republic
}

\begin{abstract}
The article describes mathematical simulation of flowing air through porous zone and water vaporisation from mentioned porous area which actually represents dried fibrous material - cotton towel. Simulation is based on finite volume method. Wet towel is placed in pipe and hot air flow through the towel. Water from towel is evaporated. Simulation of airflow through porous element is described first. Eulerian multiphase model is then used for simulation of water vaporisation from porous medium. Results of simulation are compared with experiment. Ansys Fluent 13.0 was used for calculation.
\end{abstract}

\section{Introduction}

Drying process is used in wide range of industrial application. Drying of textile is mainly used in commercial laundries, hotels etc. Textile is hydroscopic material which has the ability to attract water molecules. To remove water from linen is usually done by evaporation of water into hot air. Mass flow of hot air through textile can be interpreted as flow through porous zone. The mathematical modelling is a very good way how to simulate airflow through the porous medium. The porous area with defined parameters can be represented as linen - cotton towel. Porous parameters and next inputs for simulation are derived from the real experiment [2], [4]. The mathematical model of wet linen is achieved by patching liquid phase into porous zone. The simulation based on finite volume method can be complemented by evaporation model in Ansys Fluent so liquid phase is evaporated from porous zone and drying process is simulated.

The group of authors refers about simulation of drying process realized in industry. The example of simulation process of drying is the drying of soybean [5], spraying and evaporation of particles into hot airflow [6], vacuum drying of wood [7] or drying of the iron ore pellets [8]. Mathematical modelling of multiphase flow with phase change in energy facilities is refered [9].

\section{Experiment Data - Base for Ansys Fluent Data}

The drying process and a detailed description of the measurement procedure, measuring devices and measurement results have been described in [4]. The towel was placed in the long pipe (diameter of pipe is $200 \mathrm{~mm}$ ) and fixed (length of the pipe with towel is 110 $\mathrm{mm}$ (Figure 2). The towel contained certain amount of water. The airflow through wet towel caused evaporation of water. Temperature of air was regulated by thermostat. The drying rate was measured from wet towel with using the relative humidity sensor and temperature sensor placed behind towel. The pressure sensors were placed in the same sampling points. The schema of the test shows Figure 1. Hot air flows in arrows direction.

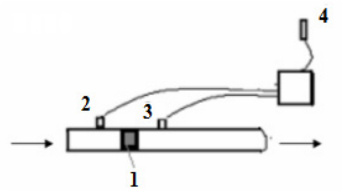

1 - wet towel

2 - temperature, flow rate and pressure sensors

3 - relative humidity, temperature and pressure sensors

4 - ambient humidity and temperature sensor

Fig. 1. Experimental equipment.
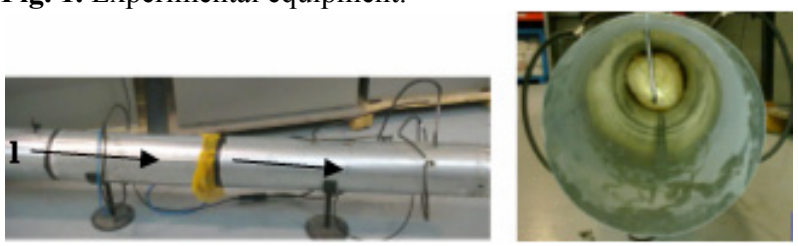

Fig. 2. Experiment layout with fixed towel.

Diameter of the pipe was $0,2 \mathrm{~m}$, distance between sampling points 2 and 3 was $2,14 \mathrm{~m}$. The towel was placed between sampling points 2 and 3 and length of the pipe with towel was $0,11 \mathrm{~m}$.

Water content before and after drying was defined as weight. Evaporation process removed $0,25 \mathrm{~kg}$ of water from towel (Table 1) and after the test the towel becomes totally dry. Weight of the dry towel was $0,2 \mathrm{~kg}$. Measurement of evaporation taken 16 minutes. 
Table 1. Weight of towel and water.

\begin{tabular}{|c|c|c|}
\hline $\begin{array}{c}\text { Weight - } \\
\text { wet towel }\end{array}$ & $\begin{array}{c}\text { Weight } \\
\text { after drying }\end{array}$ & $\begin{array}{c}\text { Weight } \\
\text { difference }\end{array}$ \\
\hline $0,45 \mathrm{~kg}$ & $0,2 \mathrm{~kg}$ & $0,25 \mathrm{~kg}$. \\
\hline
\end{tabular}

\section{Theory of Eulerian Model}

The main purpose of using this type of simulation model is its ability to solve each phases by multiple separate way [1]. The phases of air, water-vapour and water liquid are set in the model. To simulate drying of the wet fibrous material the phase water - liquid can be patched into porous zone and the velocity of water - liquid phase can be fixed to $0 \mathrm{~m} / \mathrm{s}$ in this zone. Air phase (with included vapour phase to simulate ambient wet air) flows through porous zone. Eulerian model also allows use the vaporisation model and water-liquid is evaporated from the porous area.

\subsection{Continuity equation}

The continuity equation for phase $q$ is described by equation (1), where $\vec{v}_{q}$ is velocity of phase $q, \gamma$ is porosity of the porous area, $\rho_{q}$ is density of the phase $q$, $\alpha_{q}$ is phase volume fraction, $m_{p q}$ is mass transfer from phase $\mathrm{p}$ to phase $q, S_{\mathrm{q}}$ is source term considered to be zero in our case [1].3.1.

$\frac{\partial\left(\gamma \alpha_{q} \rho_{q}\right)}{\partial t}+\nabla \cdot\left(\gamma \alpha_{q} \rho_{q} \vec{v}_{q}\right)=\gamma \sum_{p=1}^{n}\left(\dot{m}_{p q}-\dot{m}_{q p}\right)+\gamma S_{q}$

\subsection{Momentum equation}

Momentum balance for the phase $q$ shows (2), where $\vec{R}_{p q}$ is interaction force between phases, $\vec{F}_{q}$ is external body force, $\vec{F}_{l i f t, q}$ is lift force, $\vec{F}_{v m, q}$ is virtual mass force, $\vec{v}_{p q}$ is interphase velocity, $\tau$ is stress tensor [1].The continuity equation for phase is

$$
\begin{aligned}
& \frac{\partial\left(\gamma \alpha_{q} \rho_{q} \vec{v}_{q}\right)}{\partial t}+\nabla \cdot\left(\gamma \alpha_{q} \rho_{q} \vec{v}_{q} \vec{v}_{q}\right)=-\gamma \alpha_{q} \nabla p+\nabla \cdot\left(\gamma \tau_{q}\right)+\gamma \alpha_{q} \rho_{q} \vec{g}+ \\
& +\gamma \sum_{p=1}^{\prime \prime}\left(\vec{R}_{p q}+\dot{m}_{p q} \vec{v}_{p q}-\dot{m}_{q p} \vec{v}_{q p}\right)+\lambda\left(\vec{F}_{q}+\vec{F}_{l i j t q}+\vec{F}_{v m q}\right)+\alpha_{q}\left(\frac{\mu}{K}+\frac{C_{2} \rho}{2}\left|\vec{v}_{q}\right|\right) \vec{v}_{q}
\end{aligned}
$$

Coefficients $\mathrm{C} 2$ and $1 / \alpha$ for porous area were determined by manner described in reference [2].

\subsection{Energy equation}

Energy equation for multiphase Eulerian model has form (3), where $h_{q}$ is enthalpy of phase $q$, is heat flux, $Q_{p q}$ is intensity of heat exchange between phases $p$ and $q$ [1].

$$
\begin{aligned}
& \frac{\partial\left(\gamma \alpha_{q} \rho_{q} h_{q}\right)}{\partial t}+\nabla \cdot\left(\gamma \alpha_{q} \rho_{q} \vec{v}_{q} h_{q}\right)=-\gamma \alpha_{q} \frac{\partial\left(p_{q}\right)}{\partial t}+\gamma \tau_{q}: \nabla v_{q}-\nabla\left(\gamma \vec{q}_{q}\right)+\gamma S_{q}+ \\
& +\gamma \sum_{p=1}^{n}\left(Q_{p q}+\dot{m}_{p q} h_{p q}-\dot{m}_{q p} h_{q p}\right)
\end{aligned}
$$

Ranz - Marshall correlation (5) [1] was used for solving the heat transfer coefficient $h_{p q}$ (4) between phases air and water. Here $\kappa_{q}$ is thermal conductivity, $N u$ is Nusselt number, $d_{p}$ is particle diameter, $R e$ is Reynolds number, $\operatorname{Pr}$ is Prandtl number.

$$
\begin{gathered}
h_{p q}=\frac{6 \kappa_{q} \alpha_{p} \alpha_{q} N u_{p}}{d_{p}{ }^{2}} \\
N_{u}=2.0+0.6 R_{e}{ }^{1 / 2} \operatorname{Pr}^{1 / 3}
\end{gathered}
$$

\subsection{Ansys Fluent Evaporation model}

Momentum equation for evaporation model (6) [1] contents mass transfer expression from liquid state to gas state (evaporation). Mass transfer from gas to liquid state (condensation) is zero for our case. The symbols in equation (6) means: $\boldsymbol{v}$ is vapour index; $\boldsymbol{l}$ is liquid index; $\alpha$ is volume fraction of vapour; $\rho_{v}$ is vapour density; $\vec{V}_{v}$ is velocity of gas state; $\dot{m}_{l \rightarrow v}-\dot{m}_{v \rightarrow l}$ is evaporation rate $\left[\mathrm{kg} /\left(\mathrm{s} \cdot \mathrm{m}^{3}\right)\right]$.

$$
\frac{\partial}{\partial t}\left(\alpha \cdot \rho_{v}\right)+\nabla \cdot\left(\alpha \cdot \rho_{v} \overrightarrow{V_{v}}\right)=\dot{m}_{l \rightarrow v}-\dot{m}_{v \rightarrow l}
$$

Mass transfer for evaporation is started when saturation temperature $T_{\text {sat }}$ (input for Fluent) is exceeded by ambient temperature in certain part of domain. Mass transfer is defined by equation [1]:

$$
\dot{m}_{l \rightarrow v}=\operatorname{coeff} \cdot \alpha_{l} \rho_{l} \frac{\left(T-T_{\text {sat }}\right)}{T_{\text {sat }}}
$$

\section{Simulation in Ansys Fluent 13}

Mathematical model consists from pipe zone and from porous zone. Model is simplified and defined as 2D axisymmetric case, see Figure 4. Diameter of the pipe is $0,2 \mathrm{~m}$ and length of the porous zone is $0,11 \mathrm{~m}$.

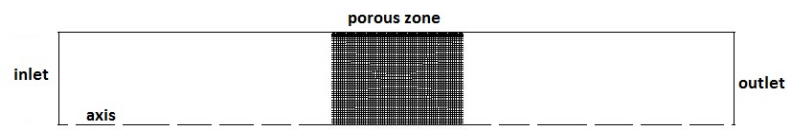

Fig. 4. Mathematical model

\subsection{Boundary conditions}

\subsubsection{Inlet of airflow and its humidity}

At the inlet the mass flow of hot wet air $(0,084 \mathrm{~kg} / \mathrm{s})$ containing the water vapour (mass fraction 0,0087) is defined. Ambient air temperature is $26{ }^{\circ} \mathrm{C}$ and relative humidity $35 \%$. Specific humidity is then $0,0075 \mathrm{~kg} / \mathrm{kg}$. Basically specie defined in the calculation as mass fraction 0,0087 represents humidity available in the air. 


\subsubsection{Inlet of air temperature}

Temperature values at inlet were measured and regulated by the thermostat, see Figure 5. Boundary condition of air temperature is driven by values from file.

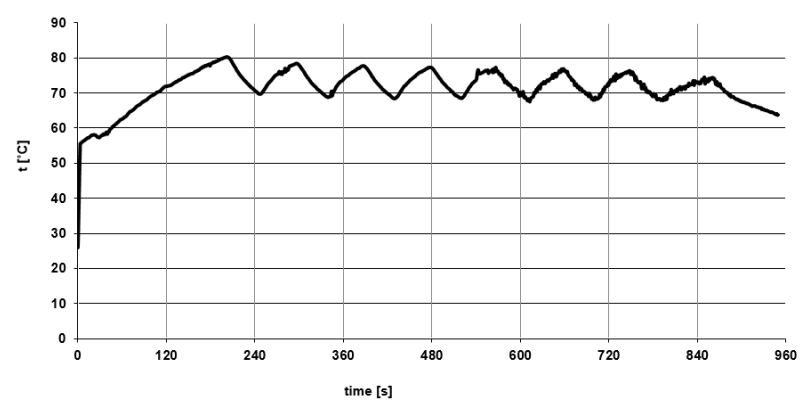

Fig. 5. Inlet temperature

\subsection{Initial conditions}

\subsubsection{Pressure and content of moisture in porous zone}

Pressure initialization is specified by value $101300 \mathrm{~Pa}$. Other important initial value is volume fraction of water in the porous zone. Practically it means moisture content in fibrous material (cotton towel). Defined volume fraction 0,058 of phase water reflects $0,25 \mathrm{~kg}$ of water in the porous area. Water droplet diameter is set to value $0,0025 \mathrm{~mm}$. It reflects good results of vaporisation process in simulation process in Fluent.

Porosity of the porous area is set to 0,95 . This value is determined on basis of experimental and numerical testing. Water phase has fixed value of velocity in porous zone $(0 \mathrm{~m} / \mathrm{s})$ so it does not move in the zone.

\subsection{Saturation temperature and pressure}

The evaporation model described in chapter 3.4 needs to define saturation temperature in terms of pressure. For saturation temperature the value of dew point is used. It corresponds to relative humidity $8 \%$ (mainly measured value in experiment) and operating temperature [4]. Table 2 shows set of values.

Table 2. Saturation temperature and pressure

\begin{tabular}{|c|c|c|}
\hline $\mathbf{t}\left[{ }^{\circ} \mathbf{C}\right]$ & $\mathbf{t}_{\text {dew }}\left[{ }^{\circ} \mathbf{C}\right]$ & $\mathbf{p}_{\mathbf{p}}[\mathbf{P a}]$ \\
\hline 50 & 6,7 & 986 \\
\hline 60 & 13,9 & 1592 \\
\hline 70 & 21 & 2491 \\
\hline 80 & 28 & 3789 \\
\hline
\end{tabular}

\section{Results of Calculation and Comparison with Experiment}

The results of the calculation are compared with data measured during experiment [4]. It is mainly pressure drop across the pipe, temperature, specific humidity, relative humidity.

\subsection{Pressure drop in the pipe}

Result of pressure drop from experiment [4] is $83 \mathrm{~Pa}$ at airflow velocity $2,37 \mathrm{~m} / \mathrm{s}$ and corresponds with result from simulation. For calculated velocity of airflow 2,66 $\mathrm{m} / \mathrm{s}$ (right part of Figure 6) the simulation shows the pressure drop $86 \mathrm{~Pa}$ (left part of Figure 6). Velocity through porous zone is modelled as a model of physical velocity [2] it leads to higher values of velocity in porous area (Figure 6).
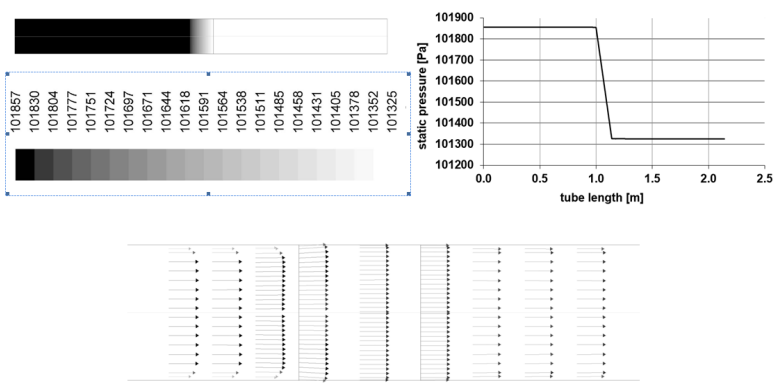

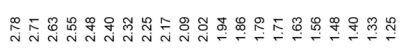

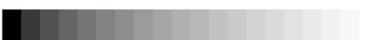

Fig. 6. Static pressure and velocity profile in porous zone

\subsection{Relative humidity}

Relative humidity indicated at the outlet varies and dependents on temperature and intensity of water evaporation. Ambient relative humidity is $35,5 \%$ at the temperature $26{ }^{\circ} \mathrm{C}$. Calculated relative humidity at outlet - Fluent shows higher values till flow time $360 \mathrm{~s}$ then it continues with values placed under measured data (Figure 7). Relative error of simulation results for certain time is shown in Table 3.

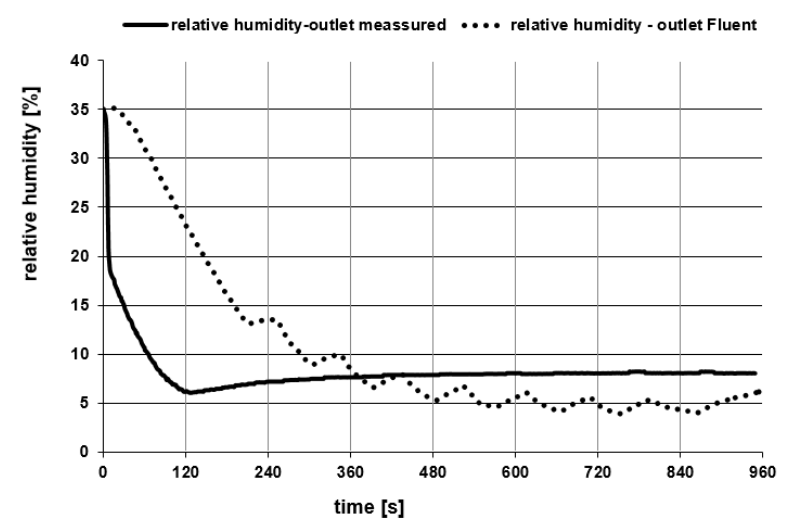

Fig. 7. Relative humidity outlet Fluent

Table 3. Relative error

\begin{tabular}{|c|c|}
\hline Flow time [s] & Relative error [\%] \\
\hline 205 & 49,2 \\
\hline 520 & 17,4 \\
\hline 920 & 30 \\
\hline
\end{tabular}




\subsection{Temperature}

Inlet temperature reported by Ansys Fluent consists from same values which was measured Figure 5. Temperature $\mathrm{t}$ - outlet is gained from experiment and is lower than at the inlet due to water evaporation. Temperature $t$ - outlet Fluent is calculated from simulation. It is lower at the beginning and with flow time rises to measured values at the outlet. This behaviour is logical and reflects results from chapter 5.1. Dew point temperature in front and behind of the towel is lower than temperature $t$ - inlet and $\mathrm{t}$ - outlet (Figure 8). It means air is not saturated and no condensation occurs, just evaporation. Relative error of calculated temperature $\mathrm{t}$ - outlet Fluent in comparison with measured temperature at the outlet for selected time is shown in Table 4.

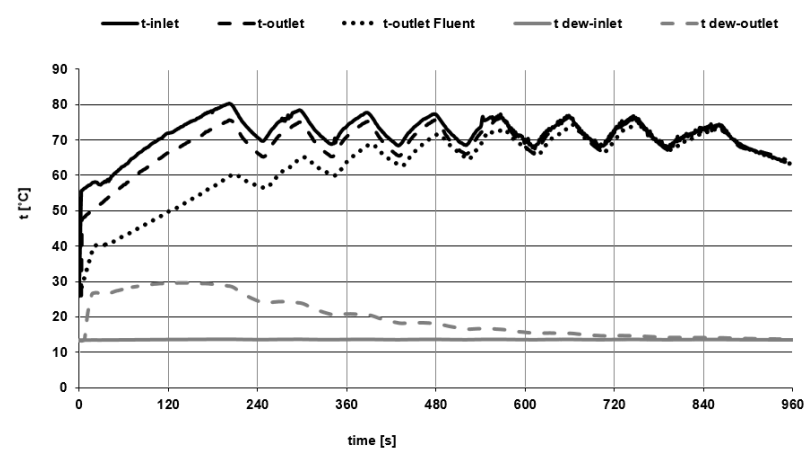

Fig. 7. Measured and calculated temperature

Table 4. Relative error

\begin{tabular}{|c|c|}
\hline Flow time [s] & Relative error [\%] \\
\hline 205 & 20,2 \\
\hline 520 & 1,2 \\
\hline 920 & 0,8 \\
\hline
\end{tabular}

\subsection{Specific humidity}

Specific humidity is derived from measured values of temperature and relative humidity at the outlet. Graph (Figure 8) show ambient specific humidity which is constant $(0,0075 \mathrm{~kg} / \mathrm{kg}$ of dry air) because amount of moisture does not change. The same situation will be at the inlet where just temperature varies but humidity does not. More interesting is state behind porous zone and at the outlet. Water is evaporated from porous zone. Measured specific humidity at the outlet is higher than calculated from time $250 \mathrm{~s}$. Results from simulation shows more intensive evaporation at the beginning and then decreasing trend. Relative error of calculated specific humidity - outlet Fluent related to measured specific humidity for selected time is shown Table 5.

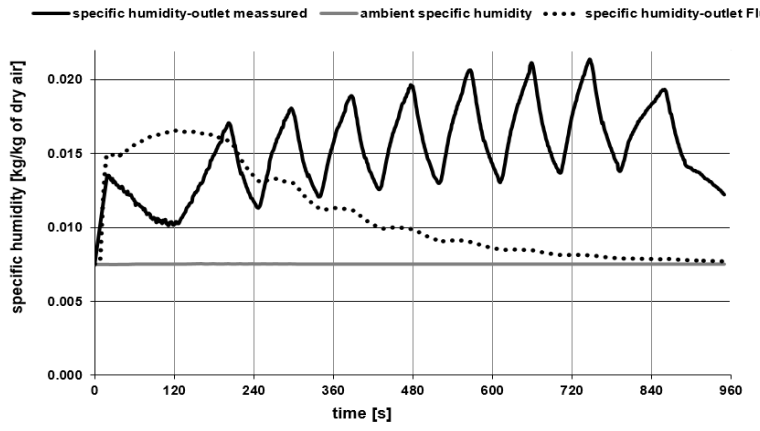

Fig. 8. Calculated and measured specific humidity

Table 5. Relative error

\begin{tabular}{|c|c|}
\hline Flow time [s] & Relative error [\%] \\
\hline 205 & 1,8 \\
\hline 520 & 23 \\
\hline 920 & 34 \\
\hline
\end{tabular}

\subsection{Volume fraction of water in porous zone}

Calculated evaporation process removes volume fraction of water from porous zone. Volume fraction patched into porous zone is set to 0,058 and it is derived from water weight in the towel $(0,25 \mathrm{~kg})$ at the beginning of experiment. At the end of calculation volume fraction is 0,0007 and it corresponds to $0,003 \mathrm{~kg}$ of water. Almost all the water is evaporated to vapour during calculation and the flow time of vaporisation is specified. The results correspond with Table 1.

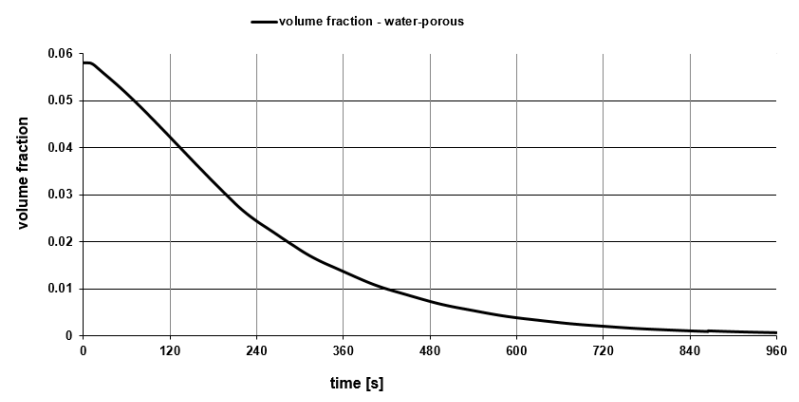

Fig. 9. Water volume fraction in porous zone vs time

\subsubsection{Contours of evaporation}

Example of evaporation (Figure 10) gives an idea how the simulation principle of drying works and that water liquid is transferred to water vapour state.

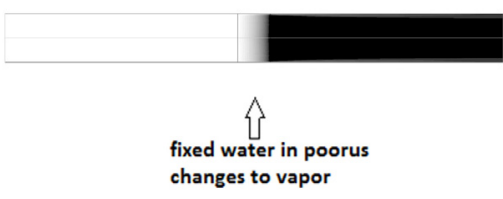

Fig. 10. Evaporation from the porous zone 


\section{Conclusions}

Mathematical simulation of drying process is continuation of the physical experiment of drying [4]. Computational case can be set in Ansys Fluent 13 by a very meaningful way. Due to ability to fix the phase velocity (water-liquid) to zero in the porous zone then the wet fibrous material can be simulated in the mathematical model. The multiphase Eulerian model, thanks of its complexity, is more than suitable for this kind of settings. Final results of the temperature and relative humidity at the outlet are close to measured values. The specific humidity which is calculated [3] has higher relative error in comparison with mathematical simulation. The simulated and measured drying process removes almost all water from linen (porous area).

\section{REFERENCES}

1. ANSYS FLUENT INC. Fluent 13.0, Help-Theory guide. Fluent Inc. (2010).

2. ANSYS FLUENT INC. Fluent 13.0, Help -User's guide. Fluent Inc. (2010).

3. MUJUMDAR, A. S.: Handbook of industrial drying, third edition, 1280 pages, (2007)

4. RASZKA, J.: The experiment of drying process of the fibrous material, Transactions of the VŠB Technical University of Ostrava, Mechanical Series No. 1, vol. LXI article No. 1996 (2015)

5. RAFIEE, S., KEYHANI, A., MOHAMMADI, A.: Soybean seeds mass transfer simulation during drying using finite element method, IDOSI publication 2008, p. 284-288, (2008).

6. HUANG, L., KUMAR, K., MUJUMDAR, A. S.: Computational fluid dynamic simulation of droplet drying in a spray dryer, Sau Paulo IDS 2004, 25.26. August, p. 326-332, (2004)

7. ERRIGUIBLE, A., BERNADA, P., COUTURE, F., ROQUES, M. A.: Modeling and numerical simulation of heat and mass transfer during vacuum drying of porous medium, Sau Paulo IDS 2004, 25.26. August, p. 726-732., (2004)

8. LJUNG, A. L..: Drying of iron ore pellets-Analysis with CFD, Lulea University of technology, (2008)

9. BOJKO, M. Metody matematického modelování vícefázového proudění s uvažováním fázových změn $v$ energetických zařizeních: teze habilitační práce $\mathrm{k}$ habilitačnímu řízení v oboru Aplikovaná mechanika. Ostrava: VŠB - Technická univerzita Ostrava, ISBN 978-80-248-3842-7 (2015) 